\title{
Personnel Policy and Practice: Sustainable Management of Pharmacy, Pharmacists and Pharmaceuticals and how to Bridge the Gap in Human Resources for Health
}

\author{
Abdeen Mustafa Omer \\ Ministry of Health and Social Welfare, Khartoum, Sudan
}

*Corresponding Author: Abdeen Mustafa Omer, Ministry of Health and Social Welfare, Khartoum, Sudan

\begin{abstract}
Worldwide there are different systems for providing pharmacy services. Most countries have some element of state assistance, either for all patients or selected groups such as children, and some private provisions. Medicines are financed either through cost sharing or full private. The role of the private services is therefore much more significant. Nationally, there is a mismatch between the numbers of pharmacists and where are they worked, and the demand for pharmacy services. The position is exacerbated locally where in some areas of poor; there is a real need for pharmacy services, which is not being met and where pharmacists have little spare capacity. Various changes within the health-care system require serious attention be given to the pharmacy human resources need. In order to stem the brain drain of pharmacists, it is, however, necessary to have accurate information regarding the reasons that make the pharmacists emigrate to the private sector. Such knowledge is an essential in making of informed decisions regarding the retention of qualified, skilled pharmacists in the public sector for long time. There are currently 3000 pharmacists registered with the Sudan Medical Council of whom only 10\% are working with the government. The pharmacist: population ratio indicates there is one pharmacist for every 11,433 inhabitants in Sudan, compared to the World Health Organisation (WHO) average for industrialised countries of one pharmacist for 2,300 inhabitants. The situation is particularly problematic in the Southern states where there is no pharmacist at all. The distribution of pharmacists indicates the majority are concentrated in Khartoum state. When population figures are taken into consideration all states except Khartoum and Gezira states are under served compared to the WHO average. This mal-distribution requires serious action as majority of the population is served in the public sector. This study reveals the low incentives, poor working conditions, job dissatisfaction and lack of professional development programmes as main reasons for the immigration to the private-sector. The objective of this communication is to highlight and provide an overview of the reasons that lead to the immigration of the public sector pharmacists to the private-sector in Sudan. The survey has been carried out in September 2004. Data gathered by the questionnaires were analysed using Statistical Package for Social Sciences (SPSS) version 12.0 for windows. The result have been evaluated and tabulated in this study. The data presented in this theme can be considered as nucleus information for executing research and development for pharmacists and pharmacy. More measures must be introduced to attract pharmacists into the public sector. The emerging crisis in pharmacy human resources requires significant additional effort to gather knowledge and dependable data that can inform reasonable, effective, and coordinated responses from government, industry, and professional associations.
\end{abstract}

Keywords: Sudan, healthcare, pharmacy, pharmacist retention, private-sector, public-sector

\section{INTRODUCTION}

Sudan is geo-politically well located, bridging the Arab world to Africa. Its large size and extension from south to north provides for several agro-ecological zones with a variety of climatic conditions, rainfall, soils and vegetation (Appendix 1). Sudan is one of the most diverse countries in Africa, home to deserts, mountain ranges, swamps and rain forests. The present policy of the national health-care system in Sudan is based on ensuring the welfare of the Sudanese inhabitants through increasing national production and upgrading the productivity of individuals. A health development strategy has been formulated in a way that realises the relevancy of health objectives to the main goals of the national development plans. The strategy of Sudan at the national level aims at developing the Primary Health Care (PHC) services in the rural areas as well as urban areas (GOS, 2002). Methods of preventing and controlling health problems are the following: 
Personnel Policy and Practice: Sustainable Management of Pharmacy, Pharmacists and Pharmaceuticals and how to Bridge the Gap in Human Resources for Health

Promotion of food supply and proper nutrition

An adequate supply of safe water and basic sanitation

Maternal and child health care

Immunisation against major infectious diseases

Preventing and control of locally endemic diseases, and

Provision of essential drugs

This will be achieved through a health system consisting of three levels (state, provincial and localities), including the referral system, secondary and tertiary levels.

Poverty and the accompanying ignorance (lacking knowledge, generally do not have many options often than exploiting their local environment) of natural resource degradation present major obstacles to sustainable development. In Sudan about $75 \%$ of the population live in poor conditions (scarcity of food, water, clothes, health services, education, etc.), while $20 \%$ live in abject poverty. Small holders and pastoral groups have intensified exploitation of the land, contributing to widespread soil erosion (Omer, 1994). The economic dividend of a full peace settlement could be great. Sudan has large areas of cultivatable land, as well as gold and cotton. Its oil reserves are ripe for further exploitation.

In Sudan, with more than ten million people do not have adequate access to health care; twenty million inhabitants are without access to pharmacy, and a very low proportion of people being treated in hospitals. The investment, which is needed to fund the extension and improvement of these services, is substantial. Most governments in developing countries are ready to admit that they lack the financial resources for proper health and pharmacy schemes. Moreover, historically, bilateral and multilateral funding accounts for less than $10 \%$ of total investment needed. Thus the need for private financing is imperative.

Many healthy utilities in developing countries need to work in earnest to improve the efficiency of operations. These improvements will not only lead to better services but also to enhanced net cash flows that can be re-invested to improve the quality of service. Staff productivity is another area where significant gains can be achieved. Failure of subsidies to reach intended objectives is due, in part, to lack of transparency in their allocation. Subsidies are often indiscriminately assigned to support investment programmes that benefit more middle and high-income families, which are already receiving acceptable service. Consumption subsidies often benefit upper-income domestic consumers' substantially more than low-income ones. Many developing countries (Sudan is not an exception) are encouraging the participation of the private sector as a means to improve productivity in the provision of health and pharmacies services. Private-sector involvement is also needed to increase financial flows to expand the coverage and quality of services. Many successful privatesector interventions have been under taken. Private operators are not responsible for the financing of works, nonetheless they can bring significant productivity gains, which would allow the utility to allocate more resources to improve and extend services. Redressing productivity, subsidy and crosssubsidy issues before the private-sector is invited to participate, has proven to be less contentious (Show and Griffin, 1995).

Despite the constraints, over the last decade the rate of implementation of rural and peri-urban pharmacy supplies and healthy programmes has increased considerably, and many people are now being served more adequately. The following are Sudan experience in pharmacy supply and healthy projects:

\section{At Community Level}

Participatory approaches in planning, implementation and monitoring.

Establishment and training of reliable financial and maintenance management.

Sensitive timing of health and hygiene education.

\section{At State and National Level}

Integrated multi-sectoral approach development.

Training approach and material development for state and extension staff. 
Continuing support from integrated multi-sectoral extension team.

Establishment of technical support system.

Multi-sectoral advisory group including training and research institutions.

Development and dissemination of relevant information for state and extension staff.

Coordination and integration of various aspects of health, and pharmacy management with other related resources is societal concern. The following are recommended:

Community must be the focus of benefits accruing from restructures, legislature to protect community interest on the basis of equity and distribution, handover the assets to the community should be examined; and communities shall encourage the transfer the management of health schemes to a professional entity.

The private-sector should be used to mobilise, and strengthen the technical and financial resources, from within and without the country to implement the services, with particular emphasis on utilisation of local resources.

The government should provide the necessary financial resources to guide the process of community management of pharmacy supplies. The government to divert from provision of services and be a facilitator through setting up standards, specifications and rules to help harmonise the private sector and establish a legal independent body by an act of parliament to monitor and control the providers. Government to assist the poor communities who cannot afford service cost, and alleviate socialeconomic negative aspects of privatisation.

The sector-actors should create awareness to the community of the roles of the private-sector and government in the provision of health and pharmacy services.

Support agencies assist with the financial and technical support, the training facilities, coordination, development and dissemination of health projects, and then evaluation of projects.

Health system in Sudan is characterised by heavily reliance on charging users at the point of access (private expenditure on health is 79.1 percent (WHO, 2004)), with less use of prepayment system such as health insurance. The way the health system is funded, organised, managed and regulated affects health workers' supply, retention, and the performance. The contested policies of public health sector reform can be construed as attempts to craft the incentive environment to produce improved performance (Hongoro and McPake, 2004). The migration of doctors to Gulf States and more recently to the UK leaves easily noticeable gap in health care system in Sudan. The loss of pharmacists from public-sector mainly to private sector could be equally detrimental.

Primary Health Care was adopted as a main strategy for health care provision in Sudan and new strategies were introduced during the last decade, include:

Health area system

Polio eradication in 1988

IMCI initiative

Rollback malaria strategy

Basic developmental need approach in 1997

Safe motherhood, making pregnancy safer initiative, eradication of harmful traditional practices and emergency obstetrics' care programmes

The 25 years pharmacy strategy aims to help people maintain their health, manage common ailments, make the best use of prescribed medicines and manage long-term medication needs by providing a service which is easily accessible to all, tailored to individual needs, efficient, co-coordinated with other professionals, and of a quality that satisfy customers (MOH, 2003). The ability of the pharmacy profession to provide patients with more support in using medicines and to make them more confident in advice they are given depends entirely on the quality and quantity of Pharmacy Human Resources (PHRs) available to do the job. The PHRs in public-sector are a critical component in the National 
Drug Policy (NDP) and the 25 years pharmacy strategy. Implementing of the pharmacy strategy and achieving its objectives depend upon people. It requires high qualified and experienced professionals, including policy-makers, pharmacists, doctors, pharmacy technicians, and paramedical staff, economists and researchers. The goals of the 25 years pharmacy strategy will not be achieved without increasing the number and quality of pharmacists working in the public-sector. The brain drain will affect the pharmacists' key role in the implementation of NDP and 25 years pharmacy strategy (MOH, 1997). Pharmacists will implement the strategy only if they understand its rationale and objectives, when they are trained to do their jobs well, paid adequate wages, and motivated to maintain high standard. Lack of appropriate expertise has been a decisive factor in the failure of some countries to achieve the objectives of national drug policy.

Although substantial new resources such as oil production, peace agreement and increased Revolving Drug Funds (RDFs) coverage are promised to health system, many of the constraints cannot be easily resolved by money alone (Appendix 2). Worldwide there are different systems for providing pharmacy services. However, viewed across a variety of characteristics, the pharmacists' profession is clearly in transition. Where this evolution is leading is not clear. Increased numbers of drug therapies, an aging but more knowledgeable and demanding population, and deficiencies in other areas of the health care system seem to be driving increased demand for the clinical counselling skills of the pharmacists. Given the growing evidence of drug related complications, however, the well documented ability of pharmacists to anticipate and forestall many of these problems. A more likely scenario is that pharmacists will be increasingly valued and demanded for their knowledge, skills and cost effectiveness contribution to the health care system (CPA, 2001). The shortage of pharmacists at points of drug dispensing deprives the population of vital expertise in the management of medicine related problems in both community and hospital setting (Matowe, et al., 2004).

The drug distribution network in Sudan consists of open market, drug vendors (known as home drug store), community (private) pharmacies, people's pharmacies, private and public hospitals, doctors' private clinics, non-governmental organisations (NGOs) clinics, private medicines importers (wholesalers), public wholesalers (i.e., Central Medical Supplies and Khartoum State Revolving Drug Fund) and local pharmaceutical manufacturers. The states' departments of pharmacy statutorily license community and Peoples' pharmacies. A superintending pharmacist, who is permanently registered with Sudan Medical Council and licensed, oversees the pharmacy any time it is opened for business (The Act, 2001). With such pharmacies there should not be any serious of the sale of fake drugs. Unfortunately however, there are many pharmacies working without qualified pharmacists (MOH, 2003).

During the last decades, the pharmacy workforces have witnessed a significant increase in the number of pharmacies, drug importing companies and pharmaceutical manufacturers as shown in Table 1.

In the public-sector, adoption of cost sharing policy as a mechanism of financing for essential medicines at full price cost requires far more expertise than simply distributing free medicines. This policy increases the demand for pharmacists in hospitals. The new concept of pharmaceutical care and recognition pharmacists as health care team members will boost the demand for the skilled PHRs. The Federal Ministry of Health (MOH) faces two major issues with the PHRs. First, there is shortage of current pharmacists in the public sector. Secondly, the future role of pharmacists within the health cares system.

Table1. Pharmacists' labour market (MOH, 2003)

\begin{tabular}{|l|l|l|l|}
\hline Institutions & 1989 & 2003 & Increase in (\%) \\
\hline Faculties of Pharmacy & 1 & 7 & $600 \%$ \\
\hline Registered Pharmacists & 1505 & 2992 & $99 \%$ \\
\hline Public Sector Pharmacists & 162 & 300 & $85 \%$ \\
\hline Hospital Pharmacies & 205 & 304 & $48 \%$ \\
\hline Community Pharmacies & 551 & 779 & $41 \%$ \\
\hline Drug Importing Companies & 77 & 175 & $127 \%$ \\
\hline Drug Manufacturers & 5 & 14 & $180 \%$ \\
\hline
\end{tabular}

As well as involving several of Sudan's neighbours, the civil war has proved costly; with the result many Sudanese have seen a fall in living standards. The political upheaval and economic meltdown in 
public-sector play an important role in driven pharmacists out. This will render the public sector remains unattractive compared with elsewhere, and the private sector will continue to suck in qualified pharmacists in increasing numbers, and the public sector will continue to finance it.

There are considerable published works about brain drain of health professionals (mainly doctors and nurses) from developing countries to the developed ones (e.g., Lerberghe et al., 2002; and Hongoro and McPake, 2004). But, there are no many empirical studies that examining the same questions about the brain drain of pharmacists from government institutions to the private-sector. The findings of this study will demonstrate factors and explain the reasons behind the brain drain of pharmacists. The data are meant to provide health officials with evidence-based information about the causes of the pharmacists' attrition. Such information is necessary for formulating appropriate policies for the retention of pharmacists in Sudanese public-sector. The study can benefit other developing countries with similar situation especially in Sub-Saharan Africa. It will also encourage human resources (planners and policy-makers) to be open to the application of business instrument when dealing with pharmacy manpower within the public sector.

\section{AIMS AND OBJECTIVES}

The main purpose of this research is to determine and analyse the reasons of pharmacists' brain drain from public to private-sectors in Sudan and to set a recommendation to remedy this situation. The specific objectives are to answer the following questions:

Why do pharmacists leave the public-sectors and what are the most important reasons, which encourage them to join the private-sector?

What are the main reasons that make public sector pharmacists have intention to quit from civil service?

What are the encouraging factors, which retain pharmacists in the public-sector?

\section{MeTHOD}

The logical target was a small sample that can describe a population group; however, the survey did not attempt to characterise the entire pharmacists working in Sudan. Thus, the objective of this study is not to generate statistically significant findings, but to explore the reasons of brain drain of pharmacists from public to private-sectors and had been sized to be feasible in the time and resources available. The information necessary to explore the reasons of brain drain of pharmacists from public to private-sectors were collected from 54 pharmacists working for private sectors (32 community pharmacies and 22 from drug importing companies) and 26 working with public sectors. All the above pharmacies were registered with the Sudan Medical Council. These samples were obtained from registered pharmacists. The samples are nevertheless, thought to be sufficient to valid the conclusion drawn from this research.

Data were collected through the use of two self-completing questionnaires: one addressed to pharmacists working with government institutions (Appendix 3), and the other from those who working with the private sector (Appendix 4). The questionnaires using close-ended questions were phrased in such a way that a limited range of response was obtained and to get reliable and consistent information. The questionnaires then pre-coded. The questionnaires were translated back into clear Arabic language. Since, the ambiguous questions would lead to responses that do not accurately capture respondents' views or not bothering to respond (Boynton, et al., 2004).

Each questionnaire was tested at the field to make sure that all relevant issues were covered and precodes were correct. Four pharmacists working with private-sector (two from community pharmacies and the other two from drug importing companies) were asked to fill the questionnaire and feed back the authors (How long did it take them to answer the questions and whether there was unclear question(s) or not?). The same scenario was repeated with two public-sector pharmacists to test the questionnaire designed to address those working with the government institutions. The pilot survey participants were not in the selected study samples. The responses were positive, though minor changes were made to both questionnaires (mainly in a formatting). A category "Others (please specify)" was added after certain questions to accommodate any response not listed. The questionnaires took the respondents from 6 to 8 minutes to be answered carefully. 
The participants from drug importing companies were selected by using systematic sampling methods. The author agreed to select the first name appears in the list of the medicines importing companies' responsible pharmacists after their ascending sorting. Thereafter, every eighth pharmacists (the total number of drug companies is 175) on the list is to complete the sample size of 22. The respondents from community pharmacies were selected from the list of licensed community pharmacies responsible pharmacists using the same procedure as in the case of drug importing companies. After the selection of the first name, every twenty-fifth pharmacists (the total number is 779 pharmacies) on the list to complete the sample of 32 participants. The electronic lists were obtained from the General Directorate of Pharmacy, and the Federal Ministry of Health - Khartoum.

Member of supportive staff within the Directorate of Pharmacy distributed the questionnaire to the pharmacies and drug companies at Khartoum State. After one week latter, all questionnaires were collected with $100 \%$ response rate. Those who work with the Federal and Khartoum State Department of Pharmacies were asked to fill in a questionnaire specially designed for those who work with the government. The questionnaire was distributed to pharmacists using internal mail system (i.e., cirque). 26 responses representing $87 \%$ of the study population were received. This study was carried out between 10th and 15th of September 2004. The questionnaire was translated back into English in order to ensure there is no loss or change in meanings. Data gathered by the questionnaires were electronically analysed using Statistical Package for Social Sciences (SPSS) version 12.0 for windows.

\section{ReSUlts}

\subsection{Public Sector Pharmacists}

The total number of respondents from public-sector was 26 pharmacists $(53.8 \%)$ of them were males. The majority $(73 \%)$ of respondents graduated within or after 1991. Most (69\%) of them had studied in Sudan. Surprisingly, $(57 \%)$ of pharmacists $(53.8 \%$ male) were employed in the private at some time in the past before joining the public-sector. This is due to the fact some of the current pharmacy managers in the Federal and Khartoum State Departments of Pharmacy had private-sector experience. The top three reasons that de-motivate pharmacists who had experience with the private were lack of ownership feeling (21.4\%), sense of working for specific person $(21.4 \%)$ and job dissatisfaction (14.3\%). Most (80.8\%) of respondents joined the public-sector due to job satisfaction and feeling of ownership (65.4\%) as illustrated in Table 2 and Figure 1. In answering the question: 'Do you have intention to leave the public-sector at some time in the future?' (61.5\%) of respondents answered 'Yes'. The vast majority $(87.5 \%)$ of them owing their intention to leave for better benefits in the private-sector compared with the public sector as given in Table 3. Table 4 shows $(69.2 \%)$ of respondents mentioned monetary issues as one of the reasons discourages them from continuing with public-sector.
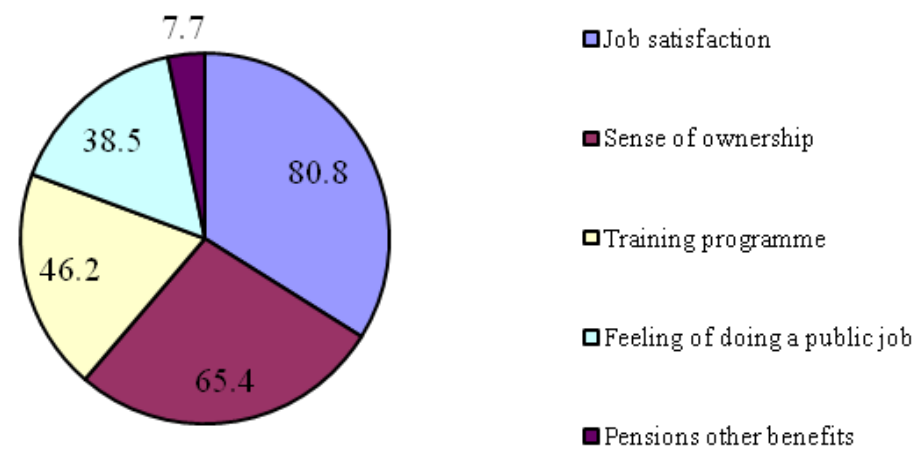

Figure1. Reasons for joining public sector

Table2. Reasons for choosing public-sector $(N=26)$

\begin{tabular}{|l|l|}
\hline Reasons & Percent \\
\hline Job satisfaction & 80.8 \\
\hline Sense of ownership & 65.4 \\
\hline Training programme & 46.2 \\
\hline Feeling of doing a public job & 38.5 \\
\hline Pensions and other benefits & 7.7 \\
\hline
\end{tabular}


Personnel Policy and Practice: Sustainable Management of Pharmacy, Pharmacists and Pharmaceuticals and how to Bridge the Gap in Human Resources for Health

Table3. 'Why are you intending to leave the public-sector?' $(N=16)$

\begin{tabular}{|l|l|}
\hline Reasons & Percent \\
\hline High wages and incentives in the private-sector & 87.5 \\
\hline Private sector offers vehicles & 56.3 \\
\hline The private give full treatment when feeling ill & 50.0 \\
\hline Job satisfaction in the private & 6.3 \\
\hline
\end{tabular}

Table4. Reasons discourage you to continue with public-sector $(N=26)$

\begin{tabular}{|l|l|}
\hline Reasons & Percent \\
\hline Monetary issues & 69.2 \\
\hline Lack of recognition of what I have done & 57.7 \\
\hline Dim vision & 53.8 \\
\hline Sense of instability & 53.8 \\
\hline Those who work and those who do not are equal & 53.8 \\
\hline Policy-makers do not care about pharmacy & 53.8 \\
\hline Lack of job satisfaction & 34.6 \\
\hline Political issues & 15.4 \\
\hline
\end{tabular}

The respondents recommended continuing pharmacy professionals' development to assure the role of the pharmacists in the health care, creation of new jobs, increase the salaries of public sector pharmacists and activation of federal pharmacy and poisons board.

\subsection{Private Sector Pharmacists}

The number of respondents from the private-sector was $54(80 \%)$ of them were male. $(77.8 \%)$ had studied in Sudan and the majority (74\%) graduated during or after 1991. $32(59.3 \%)$ of the respondents worked with community pharmacy whereas, 22 (40.7\%) were drug companies employees. Salaries in the private-sector ranged from LS 500,000 to LS 2,500,000 Sudanese pound (LS) or more (1 US\$ = LS 2500). 35 (65\%) pharmacists had previous public-sector experience. In answering the question 'Why did you leave the public sector?' (51.4\%) of respondents had left the public sector because policy-makers did not care of pharmacy (Table 5). The main reasons for choosing the private-sectors mentioned by respondents are the salaries $(61.8 \%)$; the job satisfaction $(52.9 \%)$ and the vehicle $(26.5 \%)$ are shown in Table 6 and Figure 2.

Substantial percentage $(78.4 \%)$ of the respondents answer "yes" to the question: thinking about your own job; could you leave the private and join the public sector at some time in the future? Table 7 shows the reasons, which encourage pharmacists who were in the private sector (at the time of the study), and are willing to join the public-sector.

Table5. 'Why do you leave the public-sector?' $(N=35)$

\begin{tabular}{|l|l|}
\hline Reasons & Percent \\
\hline Policy makers do not care of pharmacy & 51.4 \\
\hline Those who work and those who do not are equal & 42.9 \\
\hline Low salaries and incentives & 42.9 \\
\hline Lack of recognition of what I have done & 31.4 \\
\hline Instability feeling & 28.6 \\
\hline Lack of job satisfaction & 28.6 \\
\hline Dim vision & 25.7 \\
\hline Political issues & 17.1 \\
\hline Others* & 28.6 \\
\hline
\end{tabular}

*No training, hospitals are without medicines and domination of doctors.

Table6. Reasons for choosing the private-sector $(N=34)$

\begin{tabular}{|l|l|l|}
\hline No. & Reasons & Percent \\
\hline 1 & Salaries are better than public sector & 61.8 \\
\hline 2 & Job satisfaction & 52.9 \\
\hline 3 & Private sector offers vehicles & 26.5 \\
\hline 4 & Full treatment when feeling ill & 14.7 \\
\hline 5 & Others* & 23.5 \\
\hline
\end{tabular}

*No jobs available in the public sector and mismanagement. It is easy to have a private job to increase the income and flexibility of working environment. 
Personnel Policy and Practice: Sustainable Management of Pharmacy, Pharmacists and Pharmaceuticals and how to Bridge the Gap in Human Resources for Health

Table7. 'What encourages you to join the public-sector?' $(N=43)$

\begin{tabular}{|l|l|}
\hline Reasons & Percent \\
\hline Job satisfaction & 69.8 \\
\hline No feeling of working for specific person & 62.8 \\
\hline Overseas training & 62.8 \\
\hline Internal training & 55.8 \\
\hline Feeling of ownership & 48.8 \\
\hline Better salaries & 27.9 \\
\hline Others* & 18.6 \\
\hline
\end{tabular}

*Public sector reserves rights when ill, job satisfaction, stability and fair competition.

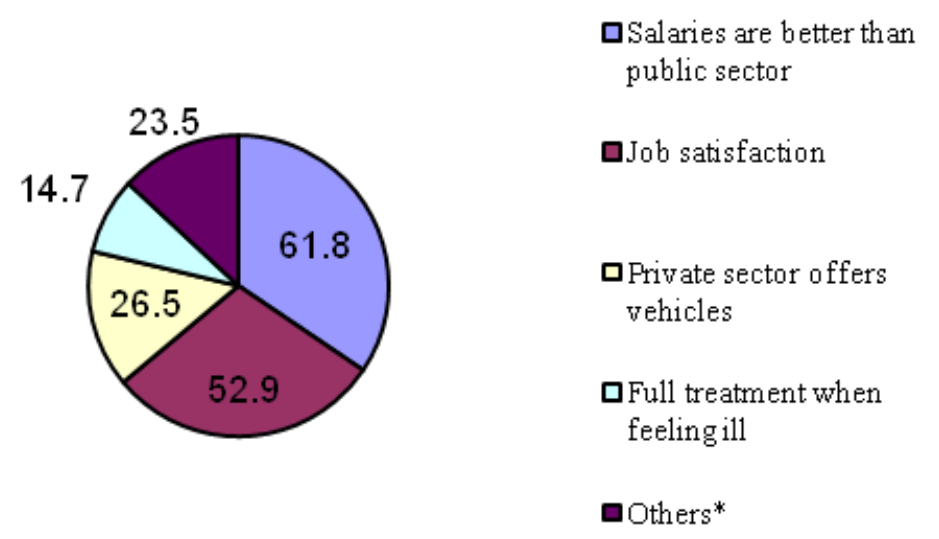

Figure2. Reasons for preferring the private-sector

The most important reasons discourage the pharmacists who were in the private-sector during the study period from joining the public-sector are presented in Table 8.

Table8. 'Why did not some private-sector pharmacists like to join the public sector?' $(N=31)$

\begin{tabular}{|l|l|}
\hline Reasons & Percent \\
\hline Monetary issues & 64.5 \\
\hline Dim vision & 51.6 \\
\hline Instability feeling & 38.7 \\
\hline Lack of job satisfaction & 19.4 \\
\hline Political issues & 12.9 \\
\hline Others* & 1.5 \\
\hline
\end{tabular}

*Government neglects pharmacists and the domination of doctors.

\section{DISCUSSIONS}

\subsection{Public Sector Pharmacy Workforces}

The public health sector reform seems to have undermined pharmacy human resources in health sector as often as making a positive contribution. Without motivated, competent, and well-funded pharmacy workforces, there is a dangerous infusion of money for establishing drugs revolving funds in different states. To address the national problem of access to essential medicines will be either misused or wasted, or both.

Challenges with respect to pharmacy human resources vary greatly between and within states, and associated with the political commitment of the states` government and their ministers of health. The public sectors' pharmacists in many states are adversely affected by sever under investment from the states and national funds, as well as external sources. For example, pharmacy budget from World Health Organisation (WHO) reduced from US\$200,000 in 2003 to only US\$ 93,000 in 2004 (MOH, 2004). Driven by financial limitations, pharmacy workforces planning at federal and states ministries of health has been unable to match pharmacists requirements, the needs of community and the health system as whole.

It has been quite evident the civil service management system is detrimental to the retention of skilled pharmacists. Like other disciplines, the service affair authority determines the number of pharmacists 
jobs in the public-sector. It also sets salary scale and other incentives schemes in coordination with the Federal Ministry of Finance and Economic Planning. Although health professionals in hospitals tend to work in shifts and have to face different working conditions, the incentive system was not flexible enough to cope with differences between health professionals and other civil servants. Notably, the gap in the pharmacy workforces do not generally relate to pharmacists, but to pharmacy assistants who constitute the bulk of the workforces. The difficulties caused by low pharmacy staff numbers are compounded by morale problems, skill balances and geographical mal-distribution, most of which are related to poor human resources management (Narasimhan, et al., 2004). How can the ministry of health grapple successfully with the demands of pharmaceutical care crises and the requirements of transformed pharmacy profession, if it lacks the very foundation of pharmacy care - motivated, trained and supported pharmacists.

\subsection{Mal-Distribution}

Around 3000 pharmacists are registered in Sudan. Only 300 (10\%) works with the public sector. 25, 25, 20 pharmacists were employed in Khartoum, Khartoum North and Omdurman hospitals respectively. Some states (e.g., Southern states has only 2 pharmacists) were not included in Table .9. This anomaly seems to imply the number of pharmacists in the public sector (has not only been insufficient in absolute terms, but also has been inefficient in its distribution). This number will be depleted and the situation may be getting worse. One reason is migration to the private-sector.

\subsection{Working Conditions}

Sudan like many developing countries, the essential working conditions is not met. Social or personal development opportunities are limited. Therefore, it is difficult for health professionals in general and pharmacists in particular to remain satisfied. The poor working conditions, remuneration and other factors pushed pharmacists out of the public-sector.

\subsection{Incentives and Remuneration}

The question 'why public-sector pharmacists intending to leave?' showed the issues of salary and remuneration dominated. (87.5\%) of pharmacists at Khartoum area stated in surveyed high wages and incentives in the private-sector. (56.3\%) stated vehicle as the reason for intending to leave the publicsector. The study revealed the salaries of the majority (78\%) of private sector pharmacists are more than 3 times the salaries of the public-sector pharmacists. On average, the private pharmacists earn L.S 2 million compared with around L.S 600,000 for the public-sector pharmacists. It is not uncommon to the public pharmacists to engage in dual practice (such as night shifts or working with the drug companies as fulltime at the same time) or solicit informal payments (such as registration of a pharmacy or a drug company without even visiting it) to supplement their income. Hence, this causes various further difficulties in accountability and equity of access.

Table9. Pharmacists' distribution at state levels

\begin{tabular}{|l|l|}
\hline State & Number of pharmacists \\
\hline Department of Pharmacy (DOP) Khartoum State* & 8 \\
\hline DOP-North Darfur & 7 \\
\hline DOP-Sennar & 2 \\
\hline DOP-North Kordofan & 5 \\
\hline DOP-South Kordofan & 7 \\
\hline DOP-White Nile & 2 \\
\hline DOP-Kassala & 7 \\
\hline DOP-River Nile & 3 \\
\hline DOP-Northern State & 3 \\
\hline DOP-Al Gezira* & 6 \\
\hline Total** & 50 \\
\hline
\end{tabular}

*The Pharmacists who work with Revolving Drug Funds are not included. **Information about other States is not available (10 Southern states, 2 Darfur states, 2 Eastern states, 1 Blue Nile state, and 1 West Kordofan state).

There are some reported evidences for using of provider incentives and enablers can improve the performance under specific circumstances. For example, Eichler and colleagues (2001) showed the 
indicators of the achievement used to establish bonus payments improved when a bonus system was introduced in Haiti. The use of financial incentives was also reported positively to change health worker behaviour in terms of heightened productivity in Cambodia (Van Damme, et al, 2001). The findings consolidate strategies implemented by Abdullah Seedahmed at Khartoum State (Federal Ministry of Health. He was the Minister of Health, Khartoum State during 1993 -2001) and Elsadig Gasmalla, at the Red Sea, Northern, Algadarif and Al Gezira States (Minister of Health, Gezira State. He was the Minister of Health during 1996 - 2000) in attracting pharmacists to work in public-sector especially, at the Ministry of Health during their time. These strategies comprised in additional to financial incentives, the full delegation of power to the pharmacy managers, political support and motivation.

\subsection{Job Satisfaction}

Without professional, personal job satisfaction, and the ability to carry out a job as well as possible, the staff can become disillusioned and leave the vacancy (Hughes, 2004). In pharmacy, where practice only remotely resembles what students are taught, this makes students frustrated and disgruntled on qualification (Matowe, et al., 2004). Thus, it is not surprising the young pharmacists (74\%) of privatesector pharmacists in the study graduated during or after 1991 seek better career opportunities in the private-sector, where they are offered at least better remuneration. The study revealed $(69.8 \%)$ of the respondents might be encouraged to join the public service, due to job satisfaction, if other obstacles are solved.

\subsection{Training Strategies}

A lack of professional development can result in low staff morale (Shepherd, 1995). Training strategies that fail to emphasise continued pharmacy professional development affect not only the numbers of pharmacists in the public-sector as shown in Table .8, but also their quality and performance. In addition, poor job satisfaction, working conditions, and remuneration. These dimensions are not captured in the data to enable international comparison. But, they are widely understood to be at least as important as more quantifiable factors in explaining the performance of the health care (Hongoro and McPake, 2004).

Although there is an imperative to retain staff, and there is a link between increased retention, personal development plan and appraisal (Gould, 2004). The strategy of bonding pharmacists to government after pre-registration training has largely failed because pharmacists easily find ways to quit from the public sector (One-year houseman-ship strategy was adopted in early 1990s). This failure is partly explained in the absence of punitive action and capacity to enforce penalties (if any) and availability of buy-out options (such as attractive drug companies).

\section{Pharmaceuticals Financing Reforms}

In developing countries, pharmaceuticals generally account for a more significant share of overall health expenditures than in developed countries (15\%). In several African countries, it is believed to exceed 50\%. In developing countries $50-90 \%$ of the overall pharmaceuticals expenditures are privately financed, which is considerably higher than in developed countries (median is 34\%) (Velasquez, et al., 1998).

Financing of pharmaceutical is crucial issue for several reasons. First, because drugs are save lives and improve health, it is important that drug financing ensures access to essential drugs for all segments of the population. Second, drugs are costly. For most ministries of health, and drugs represent the largest expenditure after staff salaries. In some countries, up to $80 \%$ of household's health-related spending is on drugs. In developing countries, drugs commonly represent from 25 to $50 \%$ of total public and private health expenditures (Quick et al., 1997). Third, inadequate funding for drugs means expenditures for staff salaries and other care costs may be used inefficiently or simply wasted. Fourth, the availability and effectiveness of drugs are key factors in generating and maintaining public interest and participation in health related activities.

To be successful, user fee mechanisms must generally be accompanied by perceived quality improvements in services. The World Bank suggests the improvement in the quality of services would compensate the negative impact of prices. This implies that improved supply mechanisms for drugs are both prerequisites and outputs of successful programmes. The properly designed cost recovery 
programmes can encourage higher demand for modern health care and, as a result, higher level of utilisation (Hotchkiss, 1998). If all are true, it is unsurprising the utilisation of Sudan health services in the public-sector was low during the 1980s and personnel, especially in peripheral health facilities, idle most of the time. In 1992, Sudan had introduced cost recovery measures as a part of its programme of economic reforms, following a course taken by many developing countries. During the 1990 `s, Sudan initiated number of initiatives to establish medicine financing mechanisms as part of health reform process and decentralised decision-making at state level. In 1992, the government abolished the constitutional right of free health care. There is interest by the states to introduce a medicine financing mechanism based on the Revolving Drug Fund (RDF) experience of Khartoum State $(\mathrm{KS})$.

Given the fact that less than $50 \%$ of the population has regular access to the essential medicines (Quick et al., 1997), and the highest availability of essential medicines at affordable prices in Khartoum state. The government decided to replicate the RDF to other states. Since 2001 the Central Medical Supplies Public Corporation (CMSPC) is involved in the development of the RDF in Seventeen states. The RDF has the highest level of political support as the president of Sudan himself inaugurated it.

\section{RECOMMENDATIONS}

The public sector is rigid, bureaucratic personnel-management practices, low incentives, poor job satisfaction and unsupportive work environment compared to the private sector. Such situation demoralised pharmacists and encourages them to join the private sector. Many (65\%) of surveyed private-sector pharmacists claimed they were public sector pharmacists migrated to the private sector. Although information on migration is sparse, anecdotal evidence persuasively underscores the problem. An internal flow of pharmacists plagues all states, since pharmacists move from poorer states to wealthier ones and from the public sector to the private. Strategies to meet current and future challenges in pharmacy human resources are urgently needed. Approaches that focus on the training of individuals, which do not take into account the job satisfaction (i.e., the nature of the work itself) and pharmacists' mobility, can enjoy only limited success. Increased production alone cannot compensate for weak motivation, high attrition and increasing mobility. To reverse decades of neglect, policy-makers in both (state and federal level) should begin now, first by recognising the problem and secondly by fixing it through the immediate implementation of potentially effective strategies. Although, we do not advocate the creation of new barriers to the movement of pharmacists between private and public-sectors, steps should be taken to redress the unbalanced situation. Ten immediate steps are recommended:

Large-scale advocacy is needed to achieve heightened political awareness within states and at federal level. One potential outcome of large-scale movement would be the beginnings of introduction of pharmacy care concept, which reshapes the pharmacy services around the patients in hospitals and community pharmacies. This concept will benefit the health care system users and motivate pharmacists to do a good job to their clients and employers. The employers need to foster an organisational culture that recognises and values staff contribution. Central to the delivery of effective recognition are employees' immediate bosses, where a participative and considerate management style is shown as a major predictive factor of retention.

The Federal Ministry of Health (FMOH) needs to learn from the past experience of Khartoum, Red Sea, Northern, and Algadarif States and current Gezira State then, identify success stories. Pharmacists and their organisations, and Ministries of Health have not remained passive in confronting the crisis in pharmacy workforces. The goodwill and commitment of public-sector pharmacists to provide quality care despite low wages (30\% of the average private salary) and medicines supply shortages at times of appalling conditions should not be overlooked.

Pharmacist job satisfaction: Job satisfaction is how people feel about their jobs. Experiencing job dissatisfaction leads to withdrawal cognition and employee turnover. Job dissatisfaction can be caused in many ways, including high centralisation, routinisation, low integration, low communication and policy knowledge. Pharmacy education has a key role to prepare pharmacy student for practice and must anticipate the changing professional role. New strategies need to be developed with the participation of pharmacy professionals associations, unions, universities and ministries of health and 
higher education representatives to meet both; the short-term and long-term needs of pharmacists as pharmacy care providers. Technology will, no doubt give opportunity to join postgraduate studies (e.g., P.G. diploma or M.Sc. courses) from overseas via e-learning or continuing pharmacy professional development programmes.

Salaries and incentives structure: This includes the process of creating new jobs, addressing low wages, as well as developing incentives structure that supports pharmacists over the course of their working lives. In order to stem the flow of pharmacists to the private-sector and increase their performance, the Ministry of Health needs to pay incentives to its pharmacy staff on a semi-private basis. Introduction of the employment contract and the application of the incentive budget line opposite performance proved to be effective in Khartoum State experience (Mohamed, 2000). The obligations of each part (employer and employee) should be written in non-ambiguous language and transparent reward system should be in place. When transparency of reward system is poor, its credibility will be questioned and pharmacists might not respond to the explicit incentive system at all. IDS, 2000 pointed the lack of training and potential career development is a particularly important contributor to voluntary resignations. Uncompetitive pay is often debated as a reason for employee turnover (IDS, 2000). The perception of receiving a fair salary is a determinant of retention. It seems to be important both at the recruitment stage and subsequently as a determinant of retention rates is the perception that employees are receiving a fair salary. It is important to note this does not necessarily equate to a large salary, since people often compare themselves with peers in the same occupations or with friends and family rather than with better paid or higher skilled workers. Also, when promises are broken and expectations are perceived (have not been met), employees take actions to withdraw from the organisation, which may include actually quitting jobs.

Pharmacy staff motivation: In addition to financial incentives, Ministry of Health should continue to invest in improving the working conditions to ensure the suitable qualified and skilled pharmacists are retained for longer periods. Recruitment of qualified pharmacists (which may include looking outside the public services). A clear definition of job assignments (staff at hospitals` level enter into written contracts to perform according to the $\mathrm{MOH}$ guidelines) and regular supervision will assist $\mathrm{MOH}$ to achieve a good staff performance. The $\mathrm{MOH}$ should provide transport to pharmacists (senior and specialised pharmacists could be offered private vehicles) from their residence to the place of work to increase their motivation. Company-paid private medical insurance, and a company car for senior staff, child day care facilities, pension and retirement plans are the most desired and lead to employee retention.

Redistribution of Pharmacy workforces: To address the problems of pharmacy profession in Sudan, an increase in access to essential medicines is insufficient. Far more important is the need to strengthen the pharmacy workforce in localities, states and federal health institutions to address the challenges and to use the resources and interventions for provision of effective pharmaceutical services.

Small staff and efficient teamwork: The pharmacy workforces are divided into two levels (1) Department of pharmacies at Ministry of Health, and (2) Hospitals. The Department of pharmacy at state level should consist of 6 pharmacists at maximum and 25 at federal department of pharmacy including drug analysis laboratory. The hospitals` department of pharmacies classified as follows:

(i) Group A includes big hospitals (e.g., Khartoum and Omdurman hospitals). The numbers of pharmacists in Group A hospitals are 15 pharmacists in addition to pharmacy assistants and other supportive staff to cover all shifts. One manager, 3 pharmacist work in Drug Information Centre, three for internal hospital pharmacy, two in outpatient pharmacy, three in people pharmacy and one in clinical pharmacist;

(ii) Group B includes medium hospitals and capital cities hospitals (e.g., Ibrahim Malik, and Medani Hospitals). The Hospital Pharmacy Department (HPD) this group managed by 4 to 6 pharmacists;

(iii) Group $\mathrm{C}$ includes small and rural hospitals. Two pharmacists could run the HPD in these hospitals. Paying attention to create more flexible and efficient system for the PHRs management in the government institutions might help improve the condition of shortages of pharmacists in the public sector. The advantages of small staff can be easily managed, trained and financed, and teamwork could be developed. This also improves the performance and productivity of the public 
sector pharmacists thereby reduces the number of the PHRs needed to provide satisfactory pharmaceutical services in the public-sector institutions. The best indicators of staff retention are the fostering of friendships at work, and managers in health cares should take time to get knowing people and foster opportunities for friendship and socialising.

National leadership at the highest level is essential and will only come to heighten the awareness of the fundamental importance of pharmacists in health care in general and in the pharmaceutical care in particular, and the development of new methods and strategies.

Continuing pharmacy professional development: The most important element of National Drug Policy (NDP) and 25 years pharmacy strategy has yet to be tackled. The MOH should fully recognise its 25 years pharmacy strategy goals could be achieved through people's (especially pharmacists) expertise. Appropriate training and development is the key to reach those goals and make strategy visions become reality. A wide variety of external (e.g., distance or e-learning in the developed world) and internal training and development programmes for pharmacists should be introduced. A pharmacist's career or pathway should be developed. A policy for active selection of training fields should be formulated according to the priorities of health care needs. The career development relies on individual training and development to enable employees to move into more challenging roles and can provide enhanced rewards for those who are promoted.

Pharmacy staff discipline and accountability system: Disciplinary procedures, which provide a range of possible responses (from warnings through dismissal, depending on the severity and frequency of the offence should be clearly stated in the new work contracts). Pharmacy managers and team leaders in different settings (administration or care providing, at both state and federal levels) should be trained to invoke disciplinary procedures and to bring criminal charges when necessary.

\section{CONCLUSION}

Improving effectiveness of the public pharmacy is by switching resources towards areas of need, reducing inequalities and promoting better health. Unless there are clear incentives for pharmacists, they can move away from public-sector.

Findings innovative approaches to stop brain drain of the pharmacists from the public sector and to increase their productivity and performance might be more appropriate strategies to solve the problem in Sudan. These strategies comprise, for instance, monitory incentives, continuing professional development, working condition and job satisfaction of civil service PHRs.

The study may help the Ministry of Health to better look at the real issues of the PHRs in the publicsector and formulate more relevant and useful policies and plans to retain qualified and skilled pharmacists in the public-sector on a solid evidence base. Monitoring and evaluation of information provided to the $\mathrm{MOH}$.

The data must be accurate and up to date. The study revealed low salaries, job dissatisfaction in relation to the pharmacy practice and bureaucracy, working conditions, lack of recognition for contribution at work, and lack of professional development training programmes are the main factors influencing the brain drain of the PHRs.

These factors affect the PHRs immigration and retention concurrently rather than in insolation.

Given the time constraints required to get the new contracting arrangements in place, there is a risk that good practice developments in options for change for change field sites may not be used effectively (continue to evaluate and disseminate the lessons that emerge from these sites).

\section{ethical Clearance and Data Protection Consent}

Before starting the data collection, ethical clearance is to be obtained from the Federal Ministry of Health Research Ethics Committee. The researchers have not time, so no ethical clearance was obtained. The respondents were informed all the data will be used for the academic research purposes only, and the data processing would not be used to support decision-making and would not cause substantial damage or distress.

\section{RESEARCH LIMITATIONS}

In the short survey pharmacists working with public and private-sectors in Sudan regarding the immigration of pharmacists from public to private-sector was meant to explore factors that discourage 
or shorten the pharmacists stay in public-sector. The design of the research itself may be considered inadequate with regard to size and selection process. However, the researchers believe it provides enough information about why pharmacists leave the public-sector. Furthermore research should be carried out to understand the scope, magnitude directions of the migratory flows, within and outside the country, as well as the characteristics and skills of the emigrated pharmacists.

This will be achieved through a health system consisting of three levels (state, provincial and localities), including the referral system, secondary and tertiary levels.

Pharmacy management should be coordinated and integrated with other various aspects of health. The following are recommended:

Community must be the focus of benefits accruing from restructures, legislature to protect community interest on the basis of equity and distribution, handover the assets to the community should be examined; and communities shall encourage the transfer the management of health schemes to a professional entity.

The private sector should be used to mobilise, and strengthen the technical and financial resources, from within and without the country to implement the services, with particular emphasis on utilisation of local resources.

The government should provide the necessary financial resources to guide the process of community management of pharmacy supplies. The government to divert from provision of services and be a facilitator through setting up standards, specifications and rules to help harmonise the private sector and establish a legal independent body by an act of parliament to monitor and control the providers. Governments to assist the poor communities who cannot afford service cost, and alleviate socialeconomic negative aspects of privatisation.

The sector actors should create awareness to the community of the roles of the private sector and government in the provision of health and pharmacy services.

Support agencies assist with the financial and technical support, the training facilities, coordination, development and dissemination of health projects, and then evaluation of projects.

\section{ACKNOWLEDGMENTS}

The author wishes to thank Gamal Ali for their valuable comments and help in setting the research instruments. Dr. Abdelgadir Head of Khartoum State Ministry of Health, Research Department and his team who assisted with data collection are gratefully acknowledged.

\section{REFERENCES}

Boynton, P.M., Wood, G.W., and Greenhalgh, T. 2004. Hands-on guide to questionnaire research: reaching beyond the white middle classes. British Medical Journal; 328: 1433-1436.

Canadian Pharmacists Association (CPA). 2001. A situation analysis of human Resources issues in the pharmacy profession in Canada. Detailed report prepared by Peartree Solutions Inc., for human resources development in Canada.

Eichler, R., Auxila, P., and Pollock, J. 2001. Output based health care: paying for performance in Haiti. Public Policy for the Private Sector. Note No. 236. World Bank. Washington DC: USA.

Gould, D. 2004. Training needs analysis: an evaluation framework. Nursing Standards 18: 33-36.

Government of Sudan (GOS). 2002. National 25 years Strategic Plan (2002-2027). Khartoum: Sudan.

Hongoro, C., and McPake, B. 2004. How to bridge the gab in human resources for health. The Lancet 364:14511459.

Hotchkiss, D.R. 1998. The trade-off between price and quality of services in the Philippines. Soc. Sci. Med. 46(2): 227-242.

Hughes, A. 2004. Devising training needs analysis toolkit. Hospital Pharmacist 11:385-88.

IDS. 2000. Personnel policy and practice: improving staff retention. Income Data Services Ltd. London: UK.

Lerberghe, WV, Ferrinho, P, Omar, MC, Blaise, P, and Bugalho, AM. 2002. When staff is underpaid: dealing with the individual coping strategies of health personnel. Bulletin of the World Health Organization 80(7): 581-584.

Matowe, L., Duwiejua, M., and Norris, P. 2004. Is there a solution to the pharmacists' brain drain from poor to rich countries? The Pharmaceutical Journal 272:98-99. 
Personnel Policy and Practice: Sustainable Management of Pharmacy, Pharmacists and Pharmaceuticals and how to Bridge the Gap in Human Resources for Health

Ministry of Health (MOH). 1997. National Drug policy. Khartoum: Sudan.

Ministry of Health (MOH). 2003. 25 years Pharmacy Strategy (2002-2027). Khartoum: Sudan. Unpublished Report.

Ministry of Health (MOH). 2004. FGDP annual report. Ministry of Health. Sudan.

Mohamed, G.K. 2000. Management of revolving drug fund: experience of Khartoum state- Sudan. M.Sc. Thesis Dissertation. The School of Pharmacy, University of Bradford: UK.

Narasimhan, V, Brown, H, Pablos-Mendez, A, Adams, O, Dussault, G, Elzinga G. 2004. Responding to the global human resources crisis. The Lancet 363:1469-1472.

Omer, A.M. 1994. Socio-Cultural aspects of water supply and sanitation in Sudan. NETWAS, Vol.2, No.4, Nairobi: Kenya.

Quick JD, Schulze, JD, Ashiru, DA, Khela, MK, Evans, DF, Patel, R and Parsons, GE. 1997. Managing drug supply: the selection, procurement, distribution and use of pharmaceuticals (2nd edition). West Hardford, CT, Kumarian Press.

Shepherd, J. 1995. Findings of training need analysis for qualified nurse practioners. Journal of Advancing Nursing 22:66-71.

Show, P.R., and Griffin, C.C. 1995. Financing health care in Sub-Saharan Africa through user fees and insurance. The World Bank. Washington D.C: USA.

The Act 2001. 2001. Pharmacy poisons and medical devices act. Ministry of Health (MOH). Khartoum: Sudan.

Van Damme W., Meessen B., and Von Schreeb J. 2001. Sotnikum New Deal. The first year better income for health staff: better service to the population. Cambodia: Medicines Sans Frontiers; Antwerp: Institute of Tropical Medicine; Phnom Penh: National Institute of Public Health; Brussels: AEDES; Cambodia: UNICEF. http://www.msf.be/fr/pdf/cambodia.pdf.

Velasquez G, Vergara, C, Mardones, C, Reyes, J, Tapia, RA, Quina, F, Atala, E. 1998. Health reform and drug financing. Health Economic and Drugs. DAP series, No. 6. WHO/ DAP/98.3.

WHO. 2004. The World Medicines Situation. WHO/EDM/PAR/2004.5. World Health Organisation (WHO): Geneva: Switzerland.

Appendix1. Facts about Sudan

\begin{tabular}{|c|c|}
\hline Full country name & Republic of the Sudan \\
\hline Total area & $\begin{array}{l}\text { One million square miles ( } 2.5 \times 106 \text { square kilometres). Land } 2.376 \times 106 \\
\text { square kilometres }\end{array}$ \\
\hline Population & 34.3 x 106 inhabitants (UN, 2004) \\
\hline Capital city & Khartoum (population 5 million) \\
\hline Language & $\begin{array}{l}\text { Arabic (official), English, Nubian, Ta Bedawie, diverse dialects of Nilotic, } \\
\text { Nilo - Hamitic, Sudanic languages }\end{array}$ \\
\hline Religions & $\begin{array}{l}\text { Sunni Muslim } 70 \% \text { (in north), indigenous beliefs } 25 \% \text {, Christian } 5 \% \\
\text { (mostly in south and Khartoum) }\end{array}$ \\
\hline GDP per head & US \$ 460 (World Bank, 2003) \\
\hline Annual growth & $4 \%$ (1997 est.) \\
\hline Inflation & $23 \%$ (1998 est.) \\
\hline Monetary unit & 1 Dinar $=10$ Sudanese pounds (1 US $\$=250$ Dinar) \\
\hline Ethnic groups & Black 52\%, Arab 39\%, Beja 6\%, Foreigners $2 \%$, others $1 \%$ \\
\hline Life expectancy & 54 years (men), 57 years (women) (UN) \\
\hline Main exports & Oil, cotton, sesame, livestock and hides, gum Arabic \\
\hline Agricultures & $\begin{array}{l}\text { Agriculture is the backbone of economic and social development. } \\
62 \% \text { of the populations are employed in agriculture. } \\
\text { Agriculture contributes } 33 \% \text { of the gross national products (GNP), and 95\% } \\
\text { of all earnings. }\end{array}$ \\
\hline Animal wealthy & $\begin{array}{l}35 \times 106 \text { head of cattle. } \\
35 \times 106 \text { head of sheep. } \\
35 \times 106 \text { head of goats. } \\
3 \times 106 \text { head of camels. } \\
0.6 \times 106 \text { head of horses and donkeys. } \\
\text { Fish wealth } 0.2 \times 106 \text { tonnes of food annually. } \\
\text { Wildlife, birds and reptiles. }\end{array}$ \\
\hline $\begin{array}{l}\text { Population access to safe water } \\
(\%) \\
\text { Population access to adequate }\end{array}$ & $\begin{array}{l}73 \% \text { (UNICEF, 1999) } \\
51 \% \text { (UNICEF, 1999) }\end{array}$ \\
\hline
\end{tabular}


Personnel Policy and Practice: Sustainable Management of Pharmacy, Pharmacists and Pharmaceuticals and how to Bridge the Gap in Human Resources for Health

\begin{tabular}{|l|l|}
\hline $\begin{array}{l}\text { sanitation (\%) } \\
\text { Population access to health } \\
\text { services (\%) }\end{array}$ & $51 \%$ (UNICEF, 1999) \\
\hline Under five mortality rate & 115 (per 1000 live births) (UNICEF, 1999) \\
\hline Environment & $\begin{array}{l}\text { Inadequate supplies of potable water, wildlife populations threatened by } \\
\text { excessive hunting, soil erosion, and desertification. }\end{array}$ \\
\hline International agreements & $\begin{array}{l}\text { Party to: Biodiversity, climate change, desertification, endangered species, } \\
\text { law of the sea, nuclear test ban, and ozone layer protection. }\end{array}$ \\
\hline
\end{tabular}

Appendix2. Summary of Inherited Problems for Health Services in Sudan

\begin{tabular}{|c|c|}
\hline Health services & Personnel \\
\hline $\begin{array}{l}\text { Absence of referral systems } \\
\text { Lack of means of patients transport and ambulances } \\
\text { Lack of work standards } \\
\text { Service is not based on the concept of client } \\
\text { satisfaction } \\
\text { Weak infrastructure and distribution } \\
\text { Lack of clear vision, mission and plans } \\
\text { Many health facilities are not constructed according to } \\
\text { the recommended standards for its location, buildings, } \\
\text { etc. } \\
\text { Low quality of tertiary services leading to patients } \\
\text { seeking treatment abroad }\end{array}$ & $\begin{array}{l}\text { Imbalance in training of different health care } \\
\text { especially technical and nursing } \\
\text { Shortage in certain specialisations such as surgery, } \\
\text { pathology, general practioners and family physician } \\
\text { High attrition rate } \\
\text { Lack of continuing education programmes } \\
\text { Poor distribution of health manpower } \\
\text { The standard of auxiliary workers does not meet the } \\
\text { required level } \\
\text { Low personnel morale, satisfaction, ownership } \\
\text { feelings, motivation, respect to work values and } \\
\text { attitude towards patients and colleagues } \\
\text { Poor culture of evidence based practice } \\
\text { Absence of clear guidelines for medical practice and } \\
\text { service protocols }\end{array}$ \\
\hline
\end{tabular}

The overall goal of the central medical supplies (CMS) ownership privatisation is to improve access to essential medicines and other medical supplies in order to improve health status of the inhabitants particularly in far states (e.g., Western and Southern States).

Establishment of alternative ownership for the CMS can be achieved by selling the majority of shares to the private sector. This will achieve the following objectives:

High access to essential medicines of good quality and affordable prices to the states' population and governments.

Efficiency and effectiveness in drug distribution system to avoid the serious pitfalls and incidences that reported during the last ten years in the CMS.

Equity by reaching all remote areas currently deprived from the formal drug distribution channels.

Improvement of the quality and quantity of delivery of medicines to the public health facilities.

The above objectives are expected to:

Increase geographical and economic access to essential medicines in all states (i.e., in both rural and urban areas) to reach at least $80 \%$ of the population (currently less than $50 \%$ of population have access to essential medicines).

The tax collection from the new business becomes more efficient and will increase after privatisation. The tax revenues could be used to finance other health-care activities.

If the government reserves some shares (not more than 50\%) in the new business, then its shares' profit could be used to finance free medicines project in hospitals outpatients' clinic, and other exempted medicines, e.g., renal dialysis and haemophilic patients' treatment.

Appendix3. Public Sector Pharmacists Brain Drain Questionnaire

Public Sector Pharmacists’ Questionnaire

Date

Department.

Serial No. 
Personnel Policy and Practice: Sustainable Management of Pharmacy, Pharmacists and Pharmaceuticals and how to Bridge the Gap in Human Resources for Health

Please mark the best answer with an X

1. Are you: 1. Male $\square$ 2. Female $\square$

2. When did you graduate?

\begin{tabular}{|c|c|}
\hline During or before 1965 & 1 \\
\hline During $1966-1970$ & 2 \\
\hline During $1971-1975$ & 3 \\
\hline During 1976 - 1980 & 4 \\
\hline During 1981 - 1985 & 5 \\
\hline During 1986 - 1990 & 6 \\
\hline During $1991-1995$ & 7 \\
\hline During $1996-2000$ & 8 \\
\hline After 2000 & 9 \\
\hline
\end{tabular}

3. Country of graduation

4. Did you experience any private job at some time in the past before joining the public sector?

1. Yes $\square$ (Go to question 5) 2. No $\square$ (Go to question 6)

5 . Why did you decide to leave the private-sector?

Please rate each of the following reasons BY CIRCLING ONE NUMBER ON EACH LINE

\begin{tabular}{|c|c|c|c|c|c|}
\hline \multicolumn{6}{|l|}{$1=$ most important, $5=$ least important } \\
\hline Job dissatisfaction & 1 & 2 & 3 & 4 & 5 \\
\hline Feeling of working for specific person & 1 & 2 & 3 & 4 & 5 \\
\hline Low salaries and incentives & 1 & 2 & 3 & 4 & 5 \\
\hline Lack of ownership & 1 & 2 & 3 & 4 & 5 \\
\hline Others (Please specify).. & & & & & \\
\hline
\end{tabular}

6. Why did you choose the public sector?

Please rate each of the following reasons BY CIRCLING ONE NUMBER ON EACH LINE.

$1=$ most important, 5 = least important

\begin{tabular}{|l|l|l|l|l|l|}
\hline Job satisfaction & 1 & 2 & 3 & 4 & 5 \\
\hline Feeling of doing a public job & 1 & 2 & 3 & 4 & 5 \\
\hline Salaries are better than the private & 1 & 2 & 3 & 4 & 5 \\
\hline
\end{tabular}


Personnel Policy and Practice: Sustainable Management of Pharmacy, Pharmacists and Pharmaceuticals and how to Bridge the Gap in Human Resources for Health

\begin{tabular}{|l|l|l|l|l|l|}
\hline Feeling of ownership & 1 & 2 & 3 & 4 & 5 \\
\hline Locally short and long training courses & 1 & 2 & 3 & 4 & 5 \\
\hline Short and long training abroad & 1 & 2 & 3 & 4 & 5 \\
\hline
\end{tabular}

7. What are the reasons that encourage you to work with public sector?

Please rate each of the following reasons BY CIRCLING ONE NUMBER ON EACH LINE.

$1=$ most important, 5 = least important

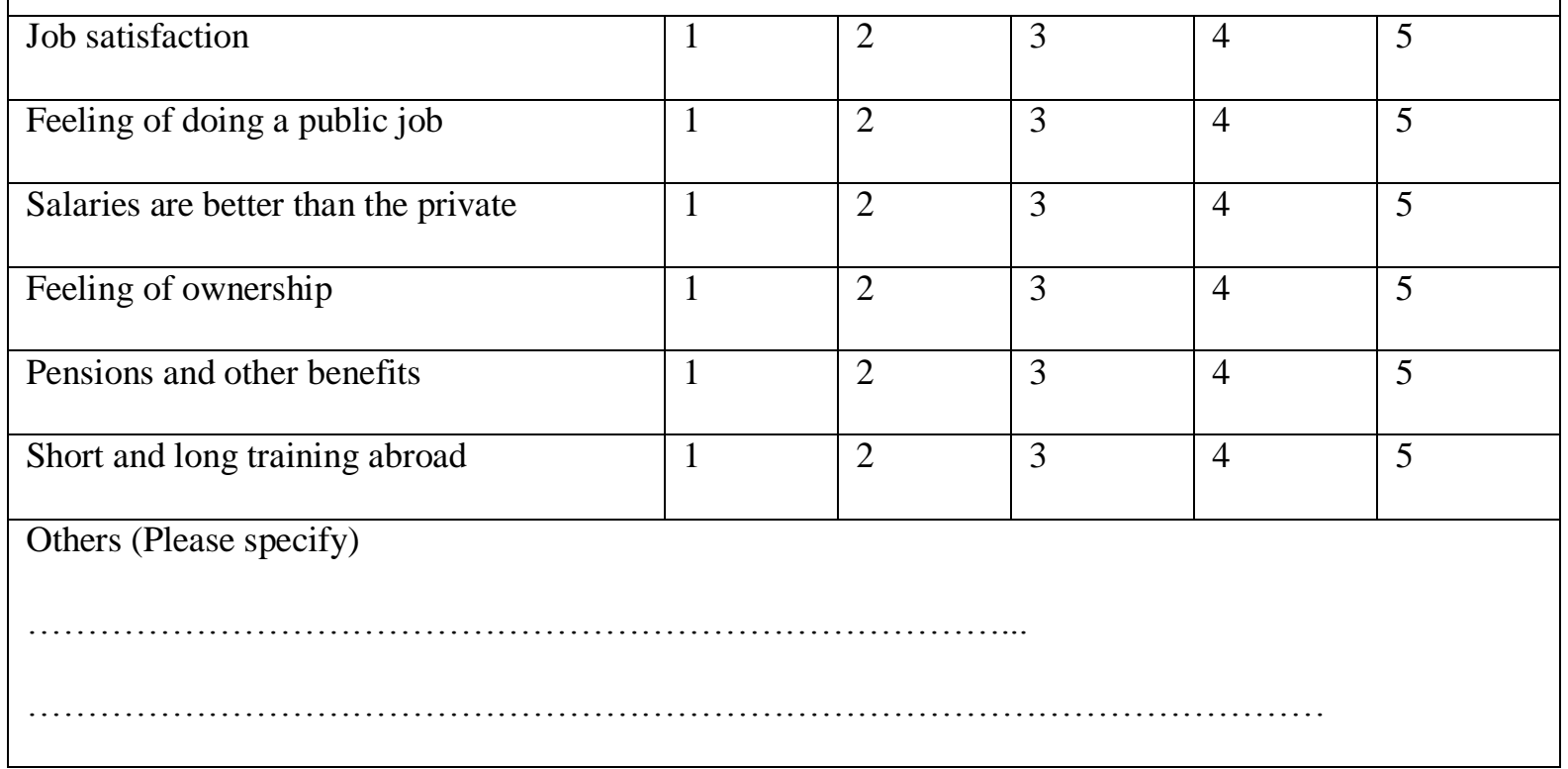

8. Do you have intention to leave the public-sector at some time in the future?

1. Yes $\square$ (Go to questions 9, 10, 11) 2. No $\square$ (Go to question 11)

9. Why are you intending to leave the public-sector?

Please rate each of the following reasons BY CIRCLING ONE NUMBER ON EACH LINE.

$1=$ most important, 5 = least important

\begin{tabular}{|l|l|l|l|l|l|}
\hline Job satisfaction in the private sector & 1 & 2 & 3 & 4 & 5 \\
\hline Private salaries are better than the public & 1 & 2 & 3 & 4 & 5 \\
\hline
\end{tabular}


Personnel Policy and Practice: Sustainable Management of Pharmacy, Pharmacists and Pharmaceuticals and how to Bridge the Gap in Human Resources for Health

\begin{tabular}{|c|c|c|c|c|c|}
\hline Private sector offers me vehicle & 1 & 2 & 3 & 4 & 5 \\
\hline $\begin{array}{l}\text { The private gives me full treatment when feeling } \\
\text { ill }\end{array}$ & 1 & 2 & 3 & 4 & 5 \\
\hline Others (Please specify) & & & & & \\
\hline
\end{tabular}

10. What are the reasons that discourage you to continue with public sector?

Please rate each of the following reasons BY CIRCLING ONE NUMBER ON EACH LINE.

$1=$ most important, 5 = least important

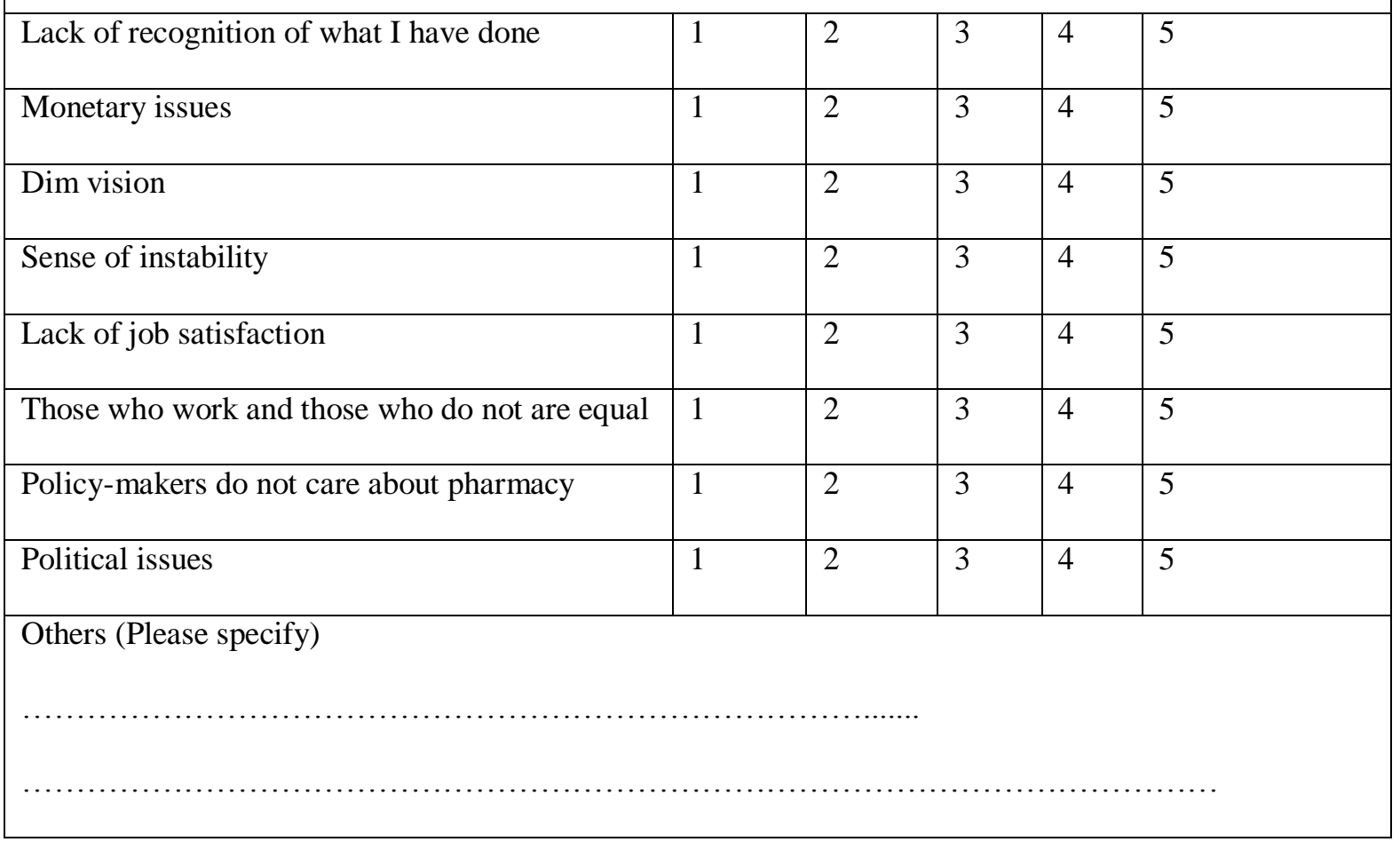

11. If you have any other comments concerning the retention of public sector pharmacy human resources. Please do not hesitate to report them.

We would like to thank you very much for your participation in our research. If you do not mind, we might need your telephone number to contact you for further clarification.

Telephone Number: 
Personnel Policy and Practice: Sustainable Management of Pharmacy, Pharmacists and Pharmaceuticals and how to Bridge the Gap in Human Resources for Health

Appendix4. Public Sector Pharmacists Brain Drain Questionnaire

Private Sector Pharmacists' Questionnaire

Date

Serial No

Please mark the best answer with an $\mathrm{X}$

1. Are you: 1 . Male $\square$ 2. Female $\square$

2. When did you graduate?

\begin{tabular}{|l|l|l|}
\hline During or before 1965 & 1 \\
\hline During 1966 - 1970 & & 2 \\
\hline During $1971-1975$ & 3 \\
\hline During $1976-1980$ & 4 \\
\hline During $1981-1985$ & & 5 \\
\hline During $1986-1990$ & 6 \\
\hline During $1991-1995$ & 7 \\
\hline During $1996-2000$ & & 8 \\
\hline After 2000 & & 9 \\
\hline
\end{tabular}

3. Country of graduation

4. What is your current employer within the private-sector?

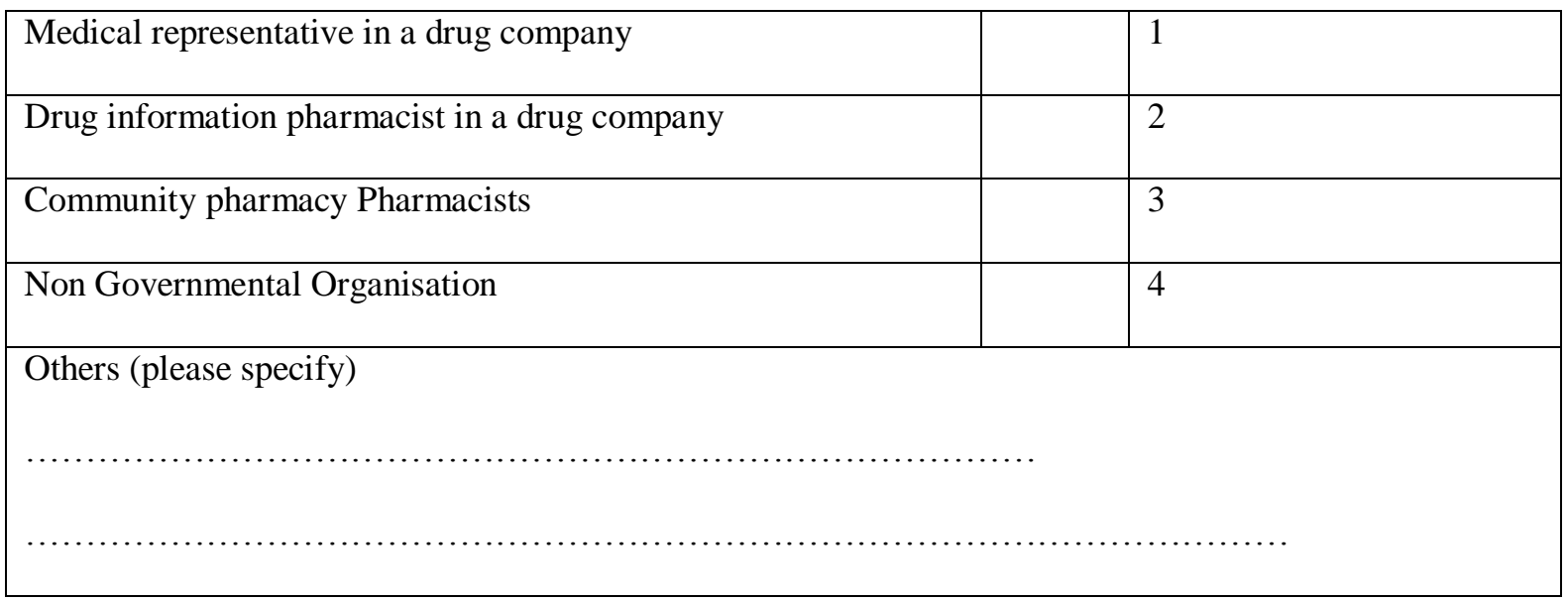

5. What is your approximate monthly salary (IN SUDANESE POUNDS)?

\begin{tabular}{|l|l|l|}
\hline Less than 500,000 & 1 \\
\hline $500,000-999,999$ & & 2 \\
\hline $1,000,000-1,499,999$ & & 3 \\
\hline
\end{tabular}


Personnel Policy and Practice: Sustainable Management of Pharmacy, Pharmacists and Pharmaceuticals and how to Bridge the Gap in Human Resources for Health

\begin{tabular}{|l|l|l|}
\hline $1,500,000-1,999,999$ & & 4 \\
\hline $2,000,000-2,499,999$ & & 5 \\
\hline $2,500,000-2,999,999$ & & 6 \\
\hline $3,000,000$ or more & & 7 \\
\hline
\end{tabular}

6. Did you work with public-sector at some time in the past before joining the private sector?

1. Yes $\square$ (Go to question 7) 2. No $\square$ (Go to question 8)

7. Why did you decide to leave the public-sector?

Please rate each of the following reasons BY CIRCLING ONE NUMBER ON EACH LINE.

\begin{tabular}{|c|c|c|c|c|c|}
\hline $1=$ most important, $5=$ least important & & & & & \\
\hline Lack of recognition of what I had done & 1 & 2 & 3 & 4 & 5 \\
\hline Low salaries and incentives & 1 & 2 & 3 & 4 & 5 \\
\hline Dim vision & 1 & 2 & 3 & 4 & 5 \\
\hline Feeling of instability & 1 & 2 & 3 & 4 & 5 \\
\hline Lack of job satisfaction & 1 & 2 & 3 & 4 & 5 \\
\hline $\begin{array}{l}\text { Those who work harder and those who do not } \\
\text { are equal }\end{array}$ & 1 & 2 & 3 & 4 & 5 \\
\hline Policy-makers do not care about pharmacy & 1 & 2 & 3 & 4 & 5 \\
\hline Political issues & 1 & 2 & 3 & 4 & 5 \\
\hline Others (Please specify) & & & & & \\
\hline
\end{tabular}

8. Why did you choose the private-sector?

Please rate each of the following reasons BY CIRCLING ONE NUMBER ON EACH LINE

\begin{tabular}{|l|l|l|l|l|l|}
\hline $1=$ most important, 5 = least important & 1 & 2 & 3 & 4 & 5 \\
\hline Job satisfaction in the private sector & 1 & 2 & 3 & 4 & 5 \\
\hline Private salaries are better than the public & 1 & 2 & 3 & 4 & 5 \\
\hline Private sector offers me vehicle & & & & & 5 \\
\hline $\begin{array}{l}\text { The private gives me full treatment when } \\
\text { feeling ill }\end{array}$ & 1 & 2 & 3 & 4 & 5 \\
\hline Others (Please specify)
\end{tabular}


Personnel Policy and Practice: Sustainable Management of Pharmacy, Pharmacists and Pharmaceuticals and how to Bridge the Gap in Human Resources for Health

9. Do you have any intention to leave the private-sector at some time in the future?

1. Yes $\square$ (Go to questions 10) 2. No $\square$ (Go to question 11)

10. What are the reasons that encourage you to join the public sector?

Please rate each of the following reasons BY CIRCLING ONE NUMBER ON EACH LINE.

\begin{tabular}{|l|l|l|l|l|l|}
\hline $1=$ most important, $5=$ least important & 1 & 2 & 3 & 4 & 5 \\
\hline Job satisfaction in the public sector & 1 & 2 & 3 & 4 & 5 \\
\hline No feeling of working for specific person & 1 & 2 & 3 & 4 & 5 \\
\hline Better salaries & 1 & 2 & 3 & 4 & 5 \\
\hline Feeling of ownership & 1 & 2 & 3 & 4 & 5 \\
\hline Overseas training & 1 & 2 & 3 & 4 & 5 \\
\hline Local training & & & & \\
\hline Others (Please specify) & &
\end{tabular}

11. What are the most important reasons that discourage you from joining the public sector at some time in the future?

Please rate each of the following reasons BY CIRCLING ONE NUMBER ON EACH LINE.

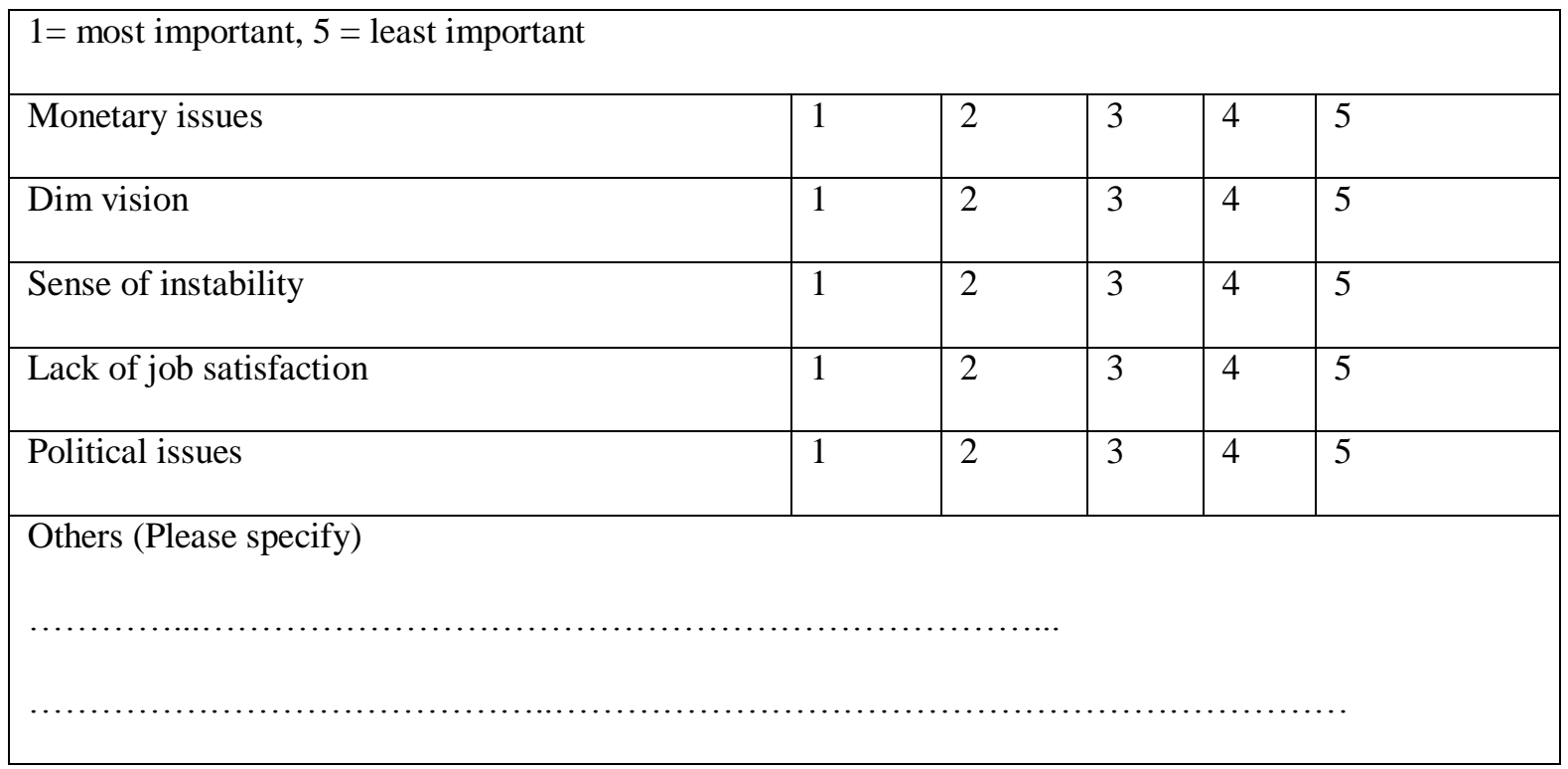


Personnel Policy and Practice: Sustainable Management of Pharmacy, Pharmacists and Pharmaceuticals and how to Bridge the Gap in Human Resources for Health

12. If you can move to the public-sector, which of the following areas you are interested in?

Please rate each of the following reasons BY CIRCLING ONE NUMBER ON EACH LINE.

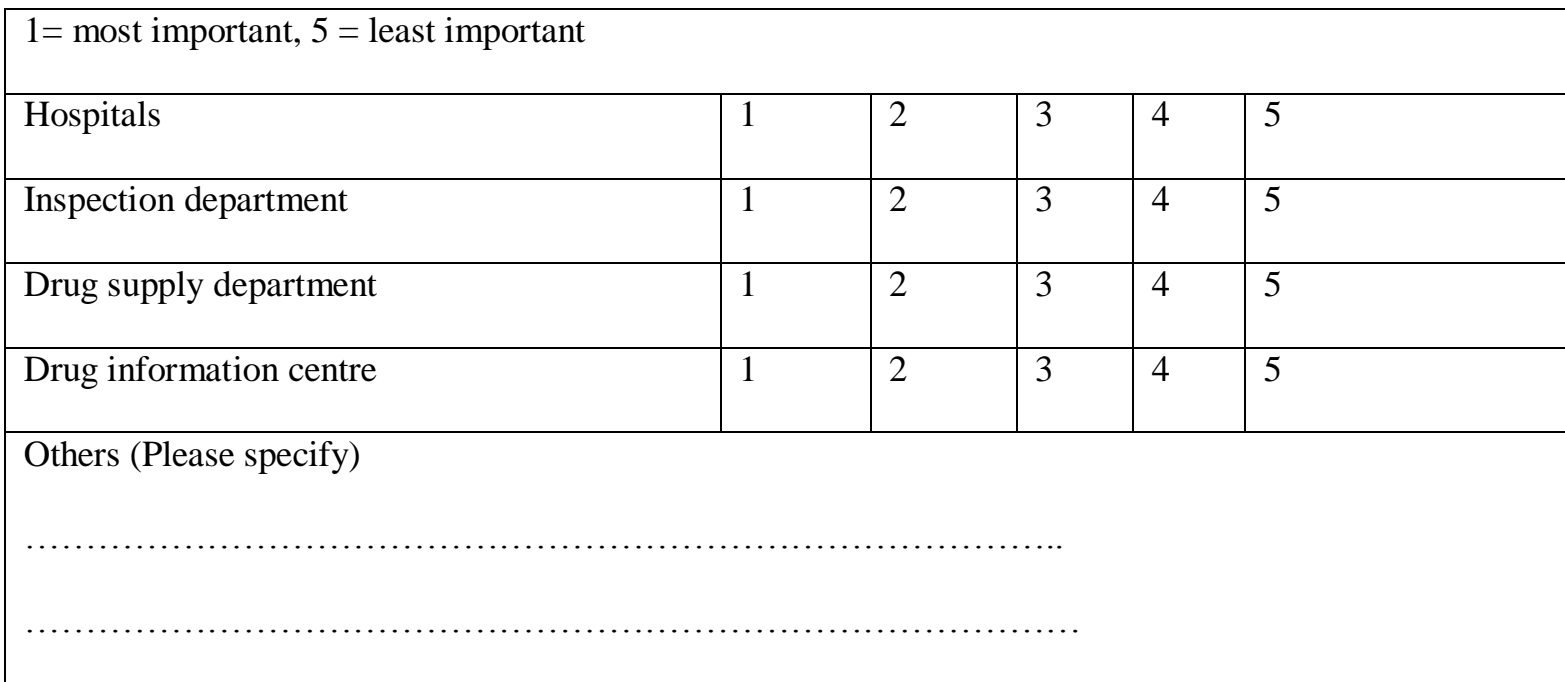

13. If you have any other comments concerning the retention of public-sector pharmacy human resources, please do not hesitate to report them.

We would like to thank you very much for your participation in our research. If you do not mind, we might need your telephone number to contact you for further clarification.

Telephone Number:

Citation: Abdeen Mustafa Omer, "Personnel Policy and Practice: Sustainable Management of Pharmacy, Pharmacists and Pharmaceuticals and how to Bridge the Gap in Human Resources for Health", International Journal of Research Studies in Biosciences (IJRSB), vol. 7, no. 2, pp. 1-23, 2019. http://dx.doi. org/10.20431/ 2349-0365. 0702001

Copyright: () 2019 Authors. This is an open-access article distributed under the terms of the Creative Commons Attribution License, which permits unrestricted use, distribution, and reproduction in any medium, provided the original author and source are credited. 